\title{
Immunogenetic heterogeneity in Type 1 (insulin-dependent) diabetes among Japanese - HLA antigens and organ-specific autoantibodies
}

\author{
K. Kida ${ }^{1}$, G. Mimura ${ }^{2}$, T. Kobayashi ${ }^{3}$, K. Nakamura ${ }^{4}$, S. Sonoda ${ }^{5}$, H. Inouye ${ }^{6}$ and K. Tsuji $^{7}$ \\ ${ }^{1}$ Department of Paediatrics, Ehime Univeristy School of Medicine, Ehime, \\ ${ }^{2}$ Second Department of Medicine, School of Medicine, University of the Ryukyus, Okinawa, \\ ${ }^{3}$ Department of Endocrinology and Metabolism, Toranomon Hospital, Tokyo, ${ }^{4}$ Department of Medicine, Kaizuka City Hospital, Osaka, \\ ${ }^{5}$ Department of Virology, Faculty of Medicine, Kagoshima University, Kagoshima, \\ ${ }^{6}$ Ehime Prefectural Institute for Public Health, Ehime and \\ ${ }^{7}$ Department of Transplantation, School of Medicine, Tokai University, Kanagawa, Japan
}

Summary. HLA phenotypes and haplotypes in relation to organ-specific autoantibody responses were studied in 82 Japanese patients with Type 1 (insulin-dependent) diabetes. HLA-DRw9 antigen and HLA phenotype of $\mathrm{DRw} 9 / \mathrm{X}$ (X: not DR4) were increased in patients with organspecific autoantibodies other than islet cell antibody $(\mathrm{CP}<0.02, \mathrm{RR}=4.02$ and $p<0.05, \mathrm{RR}=2.30$, respectively); whereas HLA-DR4 antigen and HLA phenotype of DR4/X (X: not DRw9) were increased in those without the autoantibodies $(\mathrm{CP}<0.001, \mathrm{RR}=3.95$ and $p<0.01, \mathrm{RR}=2.46$, respectively). HLA haplotype of Bw61-DRw9 was increased in patients with the autoantibodies $(p<0.005, \mathrm{RR}=4.94)$, and HLA haplotype of Bw54-DR4 was increased in those without the autoantibodies $(p<0.001, \mathrm{RR}=5.52)$. The relative risk of
HLA-DR4/DRw9 was the highest among all HLA-DR phenotypes or genotypes in patients either with or without the autoantibodies. No association was, however, found between the incidence of islet cell antibody and HLA-DR phenotypes. These findings suggest that Type 1 diabetes among Japanese is immunogenetically heterogeneous as is Type 1 diabetes among Caucasians; and the differences in HLA-association of Type 1 diabetes among ethnic groups might give a clue to understanding of a role of HLA-antigens in the development of Type 1 diabetes.

Key words: Type 1 (insulin-dependent) diabetes, HLA, autoantibodies, islet cell antibody.
It is well established that immunogenetic factors are involved in the development of Type 1 (insulin-dependent) diabetes. The immunogenetic heterogeneity in Type 1 diabetes among Caucasians has been proposed based on an HLA-association with autoimmune responses, including islet cell antibody (ICA) production [1-3] and viral infections [4], while lack of HLA association with the heterogeneity in Type 1 diabetes has also been reported [5-8]. It is known that there are a few epidemilogical differences between Type 1 diabetes among Japanese and Caucasians: the prevalence of Type 1 diabetes is as low as one in 10,000 children; girls are 1.6-fold more frequently affected than boys and the incidence of Type 1 diabetes in patients' relatives is less than $5 \%$ among Japanese [9]. The immunogenetic features of Type 1 diabetes among Japanese, however, are not well described yet [10-14]. In this study, we investigated HLA phenotypes and haplotypes in relation to autoantibody responses among Japanese Type 1 diabetic patients in order to compare immunogenetic bases for Type 1 diabetes between Japanese and Caucasians and elucidate a role of HLA-antigens in the development of Type 1 diabetes.

\section{Subjects and methods}

Eighty-two Japanese families of patients with Type 1 diabetes participated in this study after informed consent was obtained. One patient was randomly chosen for the study when there were two or more Type 1 diabetic patients in a family. Fifty-seven of 82 patients were female and 25 were male, ranging in age from 5 to 34 years. Their age of onset of the disease was 9.4 \pm 3.6 (SD) years, ranging from 1.4 to 18.0 years. Normal control subjects were 150 healthy unrelated Japanese volunteers.

HLA typing for A, B, C and DR loci was done by the standard microcytotoxicity technique [15], using the 9th International Histocompatibility Workshop typing sera or local sera standardised against these sera. As family members of normal control subjects were not typed for HLA, the distributions of HLA haplotypes and HLA-DR genotypes in Japanese normal control subjects were cited from the data of the 8th Japan HLA Workshop [16], after HLA antigen frequencies in the data of the 8th Japan HLA Workshop and those in the present study were confirmed to be compatible with each other (Table 1).

The organ-specific autoantibodies and ICA were measured in all Type 1 diabetic patients: antithyroglobulin antibody (ATGA) and antithyromicrosome antibody (ATMA) by the haemoagglutination method, antiadrenal antibody (AAA) and antigastric antibody (AGA) by the indirect immunofluorescence technique, and ICA by the indirect immunofluorescence technique using frozen slices of human group 0 pancreata as described previously [14]. The cutoffs were 
$\times 100$ for ATGA, $\times 400$ for ATMA, $\times 40$ for AGA, $\times 1$ for AAA and $5 \mathrm{JDF}$ units for ICA. The prevalence of ATGA, ATMA, AGA and AAA in the normal population of Japanese until 35 years of the age were $0 \%(0 / 60), 1.7 \%(1 / 60), 1.7 \%(1 / 60)$ and $0 \%(0 / 100)$, respectively. Our laboratory was ranked as [A] in precision of ICA assay by the third international (stage 3) workshop on the standardisation of cytoplasmic islet cell antibodies; sensitivity was $90 \%$ and specificity was $92 \%[17]$

\section{Statistical analysis}

The statistical differences in the frequencies of HLA antigens, HLA haplotypes, HLA-DR genotypes and incidence of ICA were assessed by Fisher's exact test. The Fisher's $p$ values for HLA antigen frequencies were further corrected by the number of specificities of HLA antigens tested $(\mathrm{CP})$.

\section{Results}

\section{HLA phenotypes}

HLA-A, B, C and DR antigen frequencies were determined in 82 Type 1 diabetic patients and they were compared with those in 150 normal control subjects; selected HLA antigen frequencies are presented in Table 2. The antigen frequencies of HLA-Cwl, Bw54, DR4 and DRw9 were significantly increased $(\mathrm{CP}<0.001, \quad \mathrm{RR}=3.29, \quad \mathrm{CP}<0.001, \quad \mathrm{RR}=3.29$,

Table 1. Selected HLA antigen frequencies in Japanese normal subjects

\begin{tabular}{lcccccc}
\hline Antigen & \multicolumn{2}{c}{8 th JHWa $(n=377)$} & & \multicolumn{3}{c}{ Present study $(n=150)$} \\
\cline { 6 - 7 } \cline { 6 - 7 } & no & $\mathrm{AF}(\%)$ & & no & $\mathrm{AF}(\%)$ & $p$ \\
\hline Bw52 & 92 & 24.4 & 37 & 24.7 & NS \\
Bw54 & 64 & 17.0 & 22 & 14.7 & NS \\
Bw61 & 68 & 18.0 & 30 & 20.0 & NS \\
DR2 & 130 & 34.5 & 52 & 34.7 & NS \\
DR3 & 0 & 0 & 0 & 0 & NS \\
DR4 & 158 & 41.9 & 54 & 36.0 & NS \\
DRw9 & 107 & 28.3 & 44 & 29.3 & NS \\
\hline
\end{tabular}

a 8 th Japan HLA Workshop [16]; $\mathrm{AF}=$ antigen frequencies. $n=$ number of patients studied; $\mathrm{NS}=$ not significant
$\mathrm{CP}<0.001, \mathrm{RR}=3.43$ and $\mathrm{CP}<0.03, \mathrm{RR}=2.29$, respectively); and those of HLA-Bw52, Bw62 and DR2 were significantly decreased $(C P<0.002, \quad R R=0.16$, $\mathrm{CP}<0.005, \mathrm{RR}=0.17$ and $\mathrm{CP}<0.001, \mathrm{RR}=0.10$, respectively) in Type 1 diabetic patients. The patients who were positive for one or more organ-specific autoantibodies other than ICA had a significantly high antigen frequency of HLA-DRw9 $(\mathrm{CP}<0.02, \mathrm{RR}=4.02)$; whereas the patients who were negative for any of the autoantibodies had significantly high antigen frequencies of HLA-Cwl, Bw54 and DR4 $(\mathrm{CP}<0.001$, $\mathrm{RR}=3.52, \mathrm{CP}<0.005, \mathrm{RR}=3.82$ and $\mathrm{CP}<0.001$, $\mathrm{RR}=3.95$, respectively) (Table 2). Patients were then classified into 4 groups according to HLA-DR phenotypes; those positive for DR4 but negative for DRw9 (DR4/X), those positive for DRw9 but negative for DR4(DRw9/X), those positive for both DR4 and DRw9 (DR4/9) and those negative for either DR4 or DRw9 (DRX/X). HLA phenotype of DRw9/X was significantly increased in patients with the autoantibodies compared with that in control subjects $(p<0.05$, $\mathrm{RR}=2.30$ ), and HLA phenotype of DR $4 / \mathrm{X}$ was significantly increased in those without the autoantibodies $(p<0.01, \mathrm{RR}=2.46)$, while HLA phenotype of DR4/9 was most increased in patients either with or without the autoantibodies $(p<0.05, \mathrm{RR}=3.51$ and $p<0.05$, $\mathrm{RR}=2.77$ ) (Table 3 ). The incidences of organ-specific autoantibodies other than ICA in Type 1 diabetic patients and their HLA-DR phenotypes are presented in Table 4 . The incidence of the autoantibodies was $36.8 \%$ $(21 / 57)$ in female patients, which was significantly greater than the value of $12.0 \%(3 / 25)$ in male patients $(p<0.02)$. There was no significant association between the incidence of ICA and HLA phenotype of DRw9 or DR4 (Table 5).

\section{HLA haplotypes and HLA-DR genotypes}

HLA-B and DR haplotypes and HLA-DR genotypes were determined in 72 Type 1 diabetic patients, and they were compared with those of 377 normal control

Table 2. Selected HLA antigen frequencies in Japanese Type 1 (insulin-dependent) diabetic patients

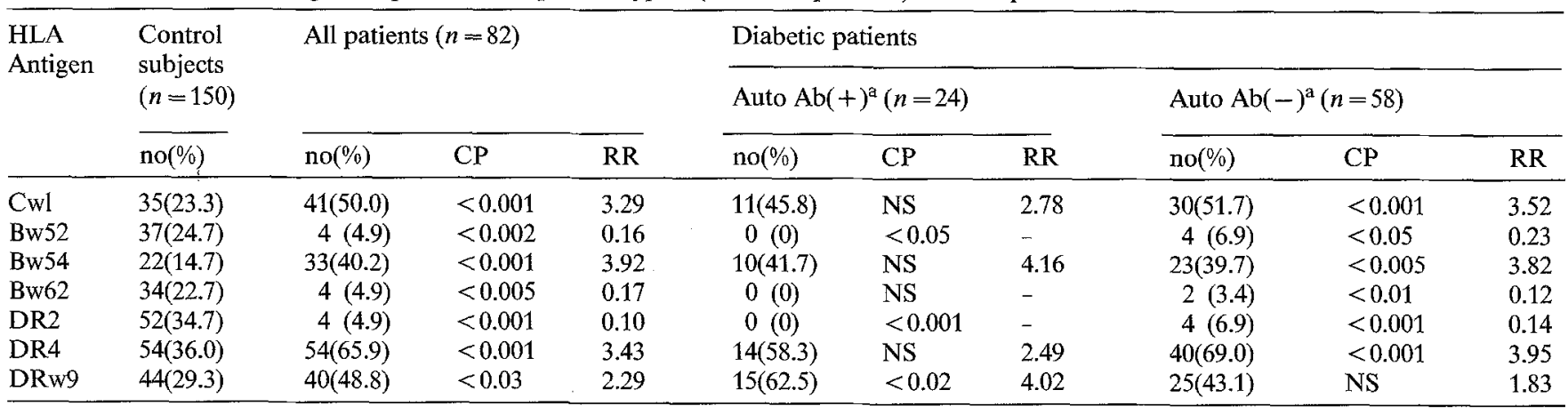

a Auto $\mathrm{Ab}=$ organ-specific autoantibodies other than $\mathrm{ICA} ; \mathrm{CP}=$ corrected $p$ value; $\mathrm{RR}=$ relative risk; $n=$ number of patients studied; $\mathrm{NS}=$ not significant; All comparisons were made against control subjects 
Table 3. HLA-DR phenotypes in Japanese Type 1 diabetic patients

\begin{tabular}{|c|c|c|c|c|c|c|c|c|c|c|}
\hline $\begin{array}{l}\text { HLA-DR } \\
\text { phenotype }\end{array}$ & $\begin{array}{l}\text { Control } \\
\text { subjects } \\
(n=150)\end{array}$ & \multicolumn{3}{|c|}{ All patients $(n=72)$} & \multicolumn{6}{|c|}{ Diabetic patients } \\
\hline $\mathrm{DR} 4 / \mathrm{X}$ & $41(27.3)$ & $31(43.1)$ & $<0.05$ & 2.01 & $8(33.0)$ & NS & 1.33 & $23(47.9)$ & $<0.01$ & 2.46 \\
\hline DRw9/X & $31(20.7)$ & $20(27.8)$ & NS & 1.48 & $9(37.5)$ & $<0.05$ & 2.30 & $11(23.0)$ & NS & 0.88 \\
\hline DR4/9 & $13(8.7)$ & $16(22.2)$ & $<0.01$ & 3.01 & $6(25.0)$ & $<0.05$ & 3.51 & $10(20.8)$ & $<0.05$ & 2.77 \\
\hline
\end{tabular}

a Auto $\mathrm{Ab}=$ organ-specific autoantibodies other than ICA; $\mathrm{RR}=$ relative risk; $\mathrm{DR} 4 \mathrm{X}=$ positive for HLA-DR4 but negative for HLA-DRw9, DRw9/X = positive for HLA-DRw9 but negative for HLA-DR4, DR4/9= positive for both HLA-DR4 and DRw9, DRX $/ \mathrm{X}=$ negative for either HLA-DR4 or DRw9; $n=$ number of patients studied; NS=not significant; All comparisons were made against control subjects

subjects obtained from the data of the 8th Japan HLA Workshop [16]. The HLA haplotypes of Bw61-DRw9 and Bw54-DR4 were significantly increased in Type 1 diabetic patients $(p<0.01, \mathrm{RR}=2.64$ and $p<0.001$, $\mathrm{RR}=4.76$, respectively). The HLA haplotype of Bw61DRw9 was increased in the patients with organ-specific autoantibodies other than ICA $(p<0.005, \mathrm{RR}=4.94)$ while the HLA haplotype of Bw54-DR4 was increased dominantly in the patients without the autoantibodies $(p<0.001, \mathrm{RR}=5.52)$ (Table 6). The relative risk ( $\mathrm{RR})$ of HLA-DRw9/DR4 was the highest among 6 HLADR genotypes (DRw9/X, DRw9/DRw9, DRw9/DR4, DR4/DR4, DR4/X and $X / X ; X$ is neither DRw9 nor DR4) in Type 1 diabetic patients either with or without the autoantibodies $(p<0.005, \mathrm{RR}=6.65$ and $p<0.001$, $\mathrm{RR}=5.25$, respectively) (Table 6). The incidence of organ-specific autoantibodies other than ICA was $60 \%$ $(3 / 5)$ in patients with HLA-DRw9 homozygously, $38.7 \%(12 / 31)$ in patients with HLA-DRw9 heterozygously and $25.0 \%(9 / 36)$ in patients without HLADRw9, although this variation of the icidence of the autoantibodies among 3 groups of patients was not statistically significant (Table 6).

\section{Discussion}

The present study has shown that HLA-DR4 and HLADRw9 are associated with Type 1 diabetes among Japanese. This is in line with previous studies reporting that HLA-DR3 and HLA-DR4 were strongly associated with Type 1 diabetes among Caucasians [18-20], except that HLA-DRw9 found in Japanese patients was substituted for HLA-DR3 in Caucasian patients. The previous studies failed to show the association of HLADRw9 with Type 1 diabetes among Japanese [13, 14]. The reason for this might be that Type 1 diabetic patients were not classified into those positive and negative for autoantibodies other than ICA in the previous studies [13, 14]. The number of autoantibodies positive patients is far less than that of autoantibodies negative patients among Japanese [21], and therefore, an increase in HLA-DRw9 found in autoantibodies positive patients might not be obvious if HLA-DR association is
Table 4. Autoantibodies and HLA-DR phenotypes in Japanese Type 1 diabetic patients

\begin{tabular}{|c|c|c|c|c|c|}
\hline \multirow[t]{2}{*}{ Auto $\mathrm{Ab}^{\mathrm{a}}$} & \multicolumn{2}{|c|}{ All patients } & \multicolumn{3}{|c|}{ Diabetic patients } \\
\hline & $\begin{array}{l}\text { Male } \\
(n=25) \\
\text { no(\%) }\end{array}$ & $\begin{array}{l}\text { Female } \\
(n=57) \\
\text { no }(\%)\end{array}$ & $\begin{array}{l}\mathrm{DR} 4 / \mathrm{X} \\
(n=38) \\
\text { no }(\%)\end{array}$ & $\begin{array}{l}\mathrm{DRw} 9 / \mathrm{X} \\
(n=24) \\
\text { no(\%) }\end{array}$ & $\begin{array}{l}\mathrm{DR} 4 / 9 \\
(n=16) \\
\operatorname{no}(\%)\end{array}$ \\
\hline ATGA & $0(0)$ & $6(10.5)$ & $1(2.6)$ & $2(8.3)$ & $2(12.5)$ \\
\hline ATMA & $3(12.0)$ & $18(31.6)$ & $6(15.8)$ & $8(33.5)$ & $6(37.5)$ \\
\hline AGA & $0(0)$ & $3(5.3)$ & $1(2.6)$ & $1(4.2)$ & $1(6.3)$ \\
\hline $\mathrm{AAA}$ & $1(4.0)$ & $2(3.5)$ & $1(2.6)$ & $2(8.3)$ & $0(0)$ \\
\hline $\begin{array}{l}\text { Any of } \\
4 \text { Auto Ab }\end{array}$ & $3(12.0)$ & $21(36.8)^{b}$ & $8(21.1)$ & $9(37.5)$ & $6(37.5)$ \\
\hline
\end{tabular}

a Auto $\mathrm{Ab}=$ autoantibodies other than ICA; ATGA $=$ antithyroglobulin antibody, ATMA = antithyromicrosome antibody, $\mathrm{AGA}=$ antigastric antibody, $\mathrm{AAA}=$ antiadrenal antibody; $\mathrm{DR} 4 / \mathrm{X}=$ positive for HLA-DR4 but negative for HLA-DRw9, DRw9/X = positive for HLA-DRw 9 but negative for HLA-DR4, DR4/9= positive for both HLA-DR4 and DRw9; $n=$ number of patients studied

b $p<0.02$ (male vs female)

Table 5. Islet cell antibody and HLA-DR phenotypes in Japanese Type 1 diabetic patients

\begin{tabular}{llll}
\hline $\begin{array}{l}\text { Duration } \\
\text { (years) }\end{array}$ & \multicolumn{3}{l}{ Incidence of ICA } \\
\cline { 2 - 4 } & $\begin{array}{l}\mathrm{DR} 4 / \mathrm{X} \\
(n=32)\end{array}$ & $\begin{array}{l}\text { DRw9/X } \\
(n=26)\end{array}$ & $\begin{array}{l}\text { DR4/9 } \\
(n=14)\end{array}$ \\
\hline$\leq 2$ & $9 / 12(75.0 \%)$ & $3 / 5(60.0 \%)$ & $5 / 5(100 \%)$ \\
$2-5$ & $7 / 18(38.9 \%)$ & $4 / 10(40.0 \%)$ & $2 / 2(100 \%)$ \\
$\geq 5$ & $1 / 10(10.0 \%)$ & $1 / 11(9.1 \%)$ & $2 / 7(28.6 \%)$ \\
\hline
\end{tabular}

DR4/X = positive for HLA-DR4 but negative for HLA-DRw9, DRw $9 / \mathrm{X}=$ positive for HLA-DRw9 but negative for HLA-DR4, DR4/9 = positive for both HLA-DR4 and DRw9

analysed in Type 1 diabetic patients in general. Recently, HLA-DR4 and DRw9 have been reported to be associated with Type 1 diabetes among Orientals including Japanese [22], which is in accord with the present study. The difference in HLA-DR phenotypes between Japanese and Caucasian Type 1 diabetic patients HLA-DRw9 among Japanese and HLA-DR3 among Caucasians - is not likely to result from the difference in the nature of Type 1 diabetes between these two races, since there are no clinical differences in Type 1 diabetes between the two races, although the prevalence of 
Table 6. HLA-DR genotypes and selected HLA haplotypes in Japanese Type 1 diabetic patients

\begin{tabular}{|c|c|c|c|c|c|c|c|c|c|c|}
\hline & $\begin{array}{l}\text { Control } \\
\text { subjects } \\
(n=377) \\
\text { no(\%) }\end{array}$ & \multicolumn{3}{|c|}{ All patients $(n=72)$} & \multicolumn{6}{|c|}{ Diabetic patients } \\
\hline \multicolumn{11}{|c|}{ HLA-DR genotypes } \\
\hline DRw9/X & $71(18.8)$ & $15(20.8)$ & NS & 1.13 & $6(25.0)$ & NS & 1.43 & $9(\mathbf{1 8 . 0})$ & NS & 0.99 \\
\hline DRw9/DRw9 & $13(3.4)$ & $5(6.9)$ & NS & 2.09 & $3(12.5)$ & NS & 4.00 & $2(4.2)$ & NS & 1.22 \\
\hline DR4/X & $120(31.8)$ & $23(31.9)$ & NS & 1.01 & $6(25.0)$ & NS & 0.71 & $17(35.4)$ & NS & 1.17 \\
\hline $\mathrm{X} / \mathrm{X}$ & $138(36.6)$ & $5(6.9)$ & $<0.001$ & 0.13 & $1(4.2)$ & $<0.001$ & 0.08 & $4(8.3)$ & $<0.001$ & 0.16 \\
\hline \multicolumn{11}{|l|}{ HLA haplotypes } \\
\hline Bw61-DRw9 & $29(7.7)$ & $13(18.1)$ & $<0.01$ & 2.64 & $7(29.2)$ & $<0.005$ & 4.94 & $5(10.4)$ & NS & 1.40 \\
\hline Bw54-DR4 & $40(10.6)$ & $26(36.1)$ & $<0.001$ & 4.76 & $6(25.0)$ & $<0.05$ & 2.81 & $19(39.6)$ & $<0.001$ & 5.52 \\
\hline
\end{tabular}

a Auto $\mathrm{Ab}=$ organ-specific autoantibodies other than ICA; ${ }^{\mathrm{b}}$ cited from the data of the 8th Japan HLA Workshop [16]; RR=relative risk; $\mathrm{NS}=$ not significant; $\mathrm{X}=$ neither DRw9 nor DR4; $n=$ number of patients studied; All comparisons were made against control subjects

Type 1 diabetes is lower by 10 - to 30 -fold in Japanese than in Caucasians [9]. Similarly, HLA-DR3 and HLADRw9 have recently been reported to be associated with Type 1 diabetes among Chinese, which are also different from HLA types of Caucasian patients [23]. Myasthenia gravis, which is an autoimmune disease directed to acetylcholine receptors of the neuromuscular junction, is similar in that its HLA-association varies among different ethnic groups; HLA-DR2 and DR3 in Caucasians [24], HLA-DR4 in Chinese [25], and HLADRw8 and DRw9 in Japanese [26]. These ethnic differences in HLA-association with Type 1 diabetes or myasthenia gravis might be derived from the difference in the distribution of HLA-DR antigens among the general population of the races; the prevalence of HLA-DR3 antigen is negligibly low not only in Type 1 diabetic patients but also in normal subjects, among Japanese as shown in the present study and previous studies $[13,14,16]$, while it is considerably high even in the general population of Caucasians $[18-20]$ and Chinese $[23,25]$.

In this study, we found that HLA phenotype of DRw9 and HLA haplotype of Bw61-DRw9 were increased in Type 1 diabetic patients who had organspecific autoantibodies other than ICA; whereas HLA phenotype of DR4 and HLA haplotype of Bw54-DR4 were increased in those who did not have any autoantibodies. Furthermore, there were a high tendency of correlation between positivity of the autoantibodies and HLA phenotypes of $\mathrm{DR} 4 / \mathrm{X}$ and $\mathrm{DRw} 9 / \mathrm{X}\left(\mathrm{X}^{2}=2.02\right.$, $p=0.15$ ) and a significant correlation between positivity of the autoantibodies and HLA haplotypes of Bw54DR4 and Bw61-DRw9 $\left(\mathrm{X}^{2}=4.19, p=0.04\right)$ in Japanese Type 1 diabetic patients. HLA types do not associate with autoantibody status (ATGA, ATMA, AGA, AAA) in the Japanese normal population [Mimura G.-unpublished data] and HLA-DRw8 but not HLA-DRw9 is associated with autoantibody responses in Japanese patient with myasthenia gravis [26]. Therefore, differences in autoantibody frequency based on HLA shown in this study is not considered to represent a phenomenon seen in the normal population but to be a specific phenomenon seen in Type 1 diabetic patients. These findings indicate that a distinction between polyendocrine autoimmune Type 1 diabetes and normal Type 1 diabetes can be made on the basis of HLA-DR phenotypes and/or HLA haplotypes. This is compatible with previous findings in Caucasians that Type 1 diabetic patients with HLA-B8/DR3 had a higher incidence of autoimmune diseases or autoantibodies than those with HLAB15/DR4 [1-3]. Contrary, there have been studies reporting lack of HLA association with polyendocrine autoimmunity in Type 1 diabetic patients of Caucasians $[7,8]$. The reason for this discrepancy is not apparent. But the distinct immunogenetic heterogeneity in myasthenia gravis based on HLA types and autoimmune responses supports an idea that different immunogenetic bases underlie the autoimmune diseases such as myasthenia gravis and Type 1 diabetes $[24,26]$.

Recently, it has been shown by a highly sensitive assay method for ATGA that a very low but significant titer of ATGA is detected in $38 \%$ of normal subjects [27]. The quantitative assessment of the relationship between autoantibody status and HLA types by a sensitive assay method may solve a discrepancy of data on it. The present study showed no association between HLA types and incidence or persistence of ICA in Japanese Type 1 diabetic patients. This confirms a previous study on ICA in Japanese Type 1 diabetic patients [14] and agrees with studies reporting no association between HLA types and persistence of ICA amongst Type 1 diabetic patients of Caucasians $[5,6]$. These are conflicting with the earlier studies reporting the association of HLA-B8/DR3 with prolonged persistence of ICA amongst Type 1 diabetic patients of Caucasians [1-3]. The reason for the discrepancy is again not apparent, but the improvement of the precision of ICA assays might be one of possible explanations for the discrep- 
ancy of data among groups of investigators [17]. Furthermore, it was reported that Type 1 diabetic patients positive for HLA-DR4 had a more severe clinical picture, a more frequent history of viral infection and a higher incidence of antibodies to Coxsakie-B virus than those negative for HLA-DR4 [4]. These findings in Japanese, as well as in Caucasians, suggest heterogeneity in the immunogenetic backgrounds unterlying Type 1 diabetes and the existence of two or more susceptibility genes for Type 1 diabetes. One gene linked to HLA-DRw9 in Japanese or HLA-DR3 in Caucasians might be involved in the regulation of the immune system and another gene linked to HLA-DR4 in both races might be related to some other unknown functions. This is supported by the fact that the relative risk of HLADRw9/DR4 heterozygote or HLA-DR3/DR4 heterozygote is the highest among the related HLA-DR genotypes in Japanese or Caucasian Type 1 diabetic patients [18-20, 28].

In the present study, there was a great increase in the frequency of HLA genotype of DR4/DRw9 but only a small increase in the frequencies of other HLA genotypes in Type 1 diabetic patients. This brings a difficulty in the interpretation of an increase in HLA-DRw9 and DR4 antigens in patients with and without the autoantibodies. But the percentages of patients who had HLA genotype of DR4/DRw9 was only $22 \%$, and therefore, other HLA genotypes could contribute to an increase in HLA-DRw9 and DR4 antigens among Type 1 diabetic patients. In fact, relative risk of HLA phenotypes of DRw9/X(X: not DR4) and DR4/X(X: not DRw9) were fairly high in Type 1 diabetic patients with and without the autoantibodies (Table 3). As the number of subjects was not large enough to analyse HLA genotypes in this study, a larger scale of investigations may solve this problem.

Recently, the polymorphism of a gene for the HLADQ $\beta$-chain has been demonstrated among Caucasian Type 1 diabetic patients by using DNA-restricting enzymes and complementary DNA probes for the HLA-DQ $\beta$-chain [29-31]. More recently, fragments of DNA for the HLA-DQ $\beta$-chain linked to HLA-DR3 and HLA-DR4, which show polymorphism in Type 1 diabetic patients, have been cloned [32] and residue 57 of HLA-DQ $\beta$-chain has been demonstrated to be responsible for an autoimmune response against $B$ cells [33]. It is thus claimed that a HLA-DQ gene is closer to Type 1 diabetes susceptibility gene(s) than a HLA-DR gene. So far as Type 1 diabetes among Japanese is concerned, further studies are necessary. It has also been recently reported that the combination of the HLA-DQ $\alpha$-chain from DQw2 and the HLA-DQ $\beta$-chain from HLA-DQw3 on a HLA-DQ molecule (transcomplementation) is demonstrated in a Caucasian Type 1 diabetic patient, and this transcomplementation of HLA-DQ molecule is suggested to contribute to the high prevalence of Type 1 diabetes with HLADR3/DR4 since HLA-DR3 is linked to HLA-DQw2 and HLA-DR4 to HLA-DQw3 [34]. Although the prevalence of Type 1 diabetes with HLA-DRw9/DR4 is high in Japanese as well, the transcomplementation of the HLA-DQ $\alpha$-and $\beta$-chain is unlikely in Japanese Type 1 diabetic patients since both HLA-DRw9 and HLA-DR4 show a linkage disequilibrium with HLADQw3 [35]. In fact, HLA-DQw3 is found in most Japanese Type 1 diabetic patients with HLADRw9/DR4, but neither HLA-DQwl nor HLA-DQw2 is found in them (unpublished data) although sub-typing of HLA-DQw3 may reveal the different HLA-DQ linkage disequilibriums between HLA-DR4 and HLADRw9 in Japanese. Further comparisons of the HLADQ $\alpha$ - and $\beta$-chain between Japanese and Caucasians might elucidate a role of transcomplementation of the HLA-DQ $\alpha$ - and $\beta$-chain in the development of Type 1 diabetes and give a further clue to understanding of HLA-associated pathogenic mechanisms for Type 1 diabetes.

\section{References}

1. Irvine WJ, McCallum CJ, Gray RS, Campbell CJ, Duncan LJP, Farquhar JW, Vaughan H, Morris PJ (1977) Pancreatic islet-cell antibodies in diabetes mellitus correlated with the duration and type of diabetes, coexistent autoimmune disease, and HLA type. Diabetes 26: 138-147

2. Bottazzo GF, Cudworth AG, Moul DJ, Doniach D, Festenstein H (1978) Evidence for a primary autoimmune type of diabetes mellitus. Br Med J 2: 1253-1255

3. Rotter JI (1981) The modes of inheritance of insulin-dependent diabetes mellitus or the genetics of IDDM, no longer a nightmare but still a headache. Am J Hum Genet 33: 835-851

4. Eberhardt MS, Wagener DK, Orchard TJ, LaPorte RE, Cavender DE, Rabin BS, Atchison RW, Kuller LH, Drash AL, Becker DJ (1985) HLA heterogeneity of insulin-dependent diabetes mellitus at diagnosis. The Pittsburgh IDDM study. Diabetes 34: 1247-1252

5. Barbosa J, Chavers B, Dunsworth T, Michael A (1982) Islet cell antibodies and histocompatibility antigens (HLA) in insulin-dependent diabetics and their first-degree relatives. Diabetes 31: $585-588$

6. Ginsberg-Fellner F, Dobersen MI, Witt ME, Rayfield EJ, Rubinstein P, Notkins AL (1982) HLA antigen, cytoplasmic islet cell antibodies, and carbohydrate tolerance in families of children with insulin-dependent diabetes mellitus. Diabetes 31: 292-298

7. Winearls BC, Bodmer JG, Bodmer WF, Bottazzo GF, MaNally J, Mann JI, Thorogood M, Smith MA, Baum JD (1984) A family study of the association between insulin dependent diabetes, autoantibodies and the HLA system. Tissue Antigens 24: 234-246

8. Hedderich U, Winkler G, Goldmann S, Scherbaum WA, Pfeiffer EF (1986) Polyendocrine autoimmunity and HLA DR-types in children with Type 1 (insulin-dependent) diabetes of long duration. Diabetologia 29: 547A

9. Kitagawa T, Fujita H, Hibi I, Aagenaes $\varnothing$, Laron Z, LaPorte RE, Tajima N, Drash AL (1984) A comparative study on the epidemiology of IDDM between Japan, Norway, Israel and the United States. Acta Paediatr Jpn 26:275-281

10. Wakisaka A, Aizawa M, Matsuura N, Nakagawa S, Nakayama E, Itakura K, Okuno A, Wagatsuma Y (1976) HLA and juvenile diabetes mellitus in the Japanese. Lancet II: 970

11. Kawa A, Nakazawa M, Sakaguchi S, Nakamura S, Kono X, Hazeki H, Kanehisa T (1977) HLA system in Japanese patients with diabetes mellitus. Diabetes 26: 591-595 
12. Sasazuki T, Kohno Y, Iwamoto I, Kosaka K, Okimoto K, Maruyama H, Isbiba S, Konishi J, Takada Y, Naito S (1978) HLA and Graves' disease or diabetes mellitus in Japan. $\mathbf{N}$ Engl J Med 298: 630-631

13. Sakurami T, Ueno Y, Nagaoka K, Kuno S, Iwaki Y, Park MS, Terasaki PI (1982) HLA-DR specifications in Japanese with juvenile-onset insulin-dependent diabetes mellitus. Diabetes 31: 105-106

14. Kobayashi T, Sugimoto T, Itoh T, Kosaka K, Tanaka T, Suwa S, Sato K, Tsuji K (1986) The prevalence of islet cell antibodies in Japanese insulin-dependent and non-insulin-dependent diabetic patients studied by indirect immunofluorescence and by a new method. Diabetes 35: 335-340

15. Terasaki PI (1970) Cytotoxicity technique. In: Brand DR, Ray JG (eds) Manual of tissue typing techniques. National Institutes of Health, Bethesda MD, pp 42-45

16. Fujii Y, Juji T, Kaibara N (1983) Family study of HLA-A, B, C and DR in Japanese. Jpn J Transplant 18: 189-203

17. Boitard C, Bonifacio E, Bottazzo GF, Gleichmann H, Molenaar J (1988) Immunology and diabetes workshops: report on the third international (stage 3) workshop on standardisation of cytoplasmic islet cell antibodies. Diabetologia 31: 451-452

18. Svejgaard A, Platz P, Ryder LP (1980) Joint report. Insulin-dependent diabetes mellitus. In: Terasaki PI (ed) Histocompatibility testing 1980. Regnets of University of California, Los Angeles, CA, pp 638-656

19. Platz P, Jakobsen BK, Morling N, Ryder LP, Svejgaard A, Thomsen M, Christy M, Kromann H, Benn J, Nerup J, Green A, Hauge M (1981) HLA-D and DR antigens in genetic analysis of insulindependent diabetes mellitus. Diabetologia 21: 108-115

20. Wolf E, Spencer KM, Cudworth AG (1983) The genetic susceptibility to Type 1 (insulin-dependent) diabetes: analysis of the HLA-DR association. Diabetologia 24: 224-230

21. Kida K, Mimura G (1987) Immunogenetic bases for insulin-dependent diabetes mellitus. In: Japan Diabetic Society (ed) Progress in diabetology 1987. Shindan-to-Chiryo-sha, Tokyo, pp 202-210

22. Bertrams J, Baur MP (1984) Disease reports, insulin-dependent diabetes mellitus. In: Albert ED, Baur MP, Mayr WR (eds) Histocompatibility testing 1984. Report on the Ninth International Histocompatibility workshop and Conference. Springer, Berlin Heidelberg New York, pp 348-358

23. Hawkins BR, Lam KSL, Ma JTC, Low LCK, Cheung PT, Serjeantson SW, Yeung RTT (1987) Strong association of HLADR3/DRw9 heterozygosity with early-onset insulin-dependent diabetes mellitus in Chinese. Diabetes 36: 1297-1300

24. Compston DAS, Vincent A, Newsom-Davis J, Batchelor JR (1980) Clinical, pathological, HLA antigen and immunological evidence for disease heterogeneity in myasthenia gravis. Brain 103: 579-601
25. Lee TD, Zhao TM, Bu KJ, Lu CZ, O'Donnell M, Sandler SG (1984) Association of HLA-DR4 with myasthenia gravis in the Chinese. Tissue Antigens 23: 127-129

26. Kida K, Hayashi M, Yamada I, Matsuda H, Yoshinaga J, Takami S, Yashiki S, Sonoda S (1987) Heterogeneity in myasthenia gravis: HLA phenotypes and autoantibody responses in ocular and generalized types. Ann Neurol 21: 274-278

27. Kohno T, Tsunetoshi Y, Ishikawa E (1988) Existence of anti-thyroglobulin IgG in healthy subjects. Biochem Biophys Res Comm 155: 224-229

28. Rotter JI, Anderson CE, Rubin R, Congleton JE, Terasaki PI, Rimoin DL (1983) HLA genotypic study of insulin-dependent diabetes. The excess of DR3/DR4 heterozygotes allows rejection of the recessive hypothesis. Diabetes 32: 169-174

29. Owerbach D, Lernmark $\AA$, Platz P, Ryder LP, Rask L, Peterson PA, Ludvigsson $J$ (1983) HLA-D region $\beta$-chain DNA endonuclease fragments differ between HLA-DR identical healthy and insulin-dependent diabetic individuals. Nature 303: 815-817

30. Cohen-Haguenauer O, Robbins E, Massart C, Busson M, Deschamps I, Hors J, Lalouel JM, Dausset J, Cohen D (1985) A systematic study of HLA class II- $\beta$ DNA restriction fragments in insulin-dependent diabetes mellitus. Proc Natl Acad Sci USA 82: 3335-3339

31. Böhme J, Carlsson B, Wallin J, Möller E, Persson B, Peterson PA, Rask L (1986) Only one DQ- $\beta$ restriction fragment pattern of each DR specificity is associated with insulin-dependent diabetes. $J$ Immunol 137: 941-947

32. Michelsen B, Lernmark A (1987) Molecullar cloning of a polymorphic DNA endonuclease fragment associates insulin-dependent diabetes mellitus with HLA-DQ. J Clin Invest 79: 1144-1152

33. Todd JA, Bell JI, McDevitt HO (1987) HLA-DQ $\beta$ gene contributes to susceptibility and resistance to insulin-dependent diabetes mellitus. Nature 329: 599-604

34. Nepom BS, Schwarz D, Palmer JP, Nepom GT (1987) Transcomplementation of HLA genes in IDDM. HLA-DQ $\alpha$ - and $\beta$-chain produce hybrid molecules in DR $3 / 4$ heterozygotes. Diabetes 36 : 114-117

35. Dausset J, Cohen D (1984) HLA at the gene level. In: Albert ED, Baur MP, Mayer WR (ed) Histocompatibility testing 1984. Springer, Berlin Heidelberg New York, pp 22-28

Received: 28 June 1988

and in revised form: 16 November 1988

\section{Dr. K. Kida}

Department of Paediatrics

Ehime University School of Medicine

Shigenobu, Ehime 791-02

Japan 